\title{
STRUCTURAL AND KINEMATIC ANALYSIS OF RATCHET MECHANISM THAT ACTS ON CHAIN CONVEYOR OF MANURE SPREADER
}

\author{
Popa Lucretia $^{1}$, Dudici Luciana ${ }^{2}$, Nedelcu Ancuta ${ }^{1}$, Stefan Vasilica $^{1}$
}

${ }^{1}$ National Institute of Research - Development for Machines and Installations Designed to Agriculture and Food Industry, Romania; ${ }^{2}$ Politehnica University of Bucharest, Romania lucretia_popa@yahoo.com, luciana_ionita@yahoo.com, nedelcuus@yahoo.com, alle_vali@yahoo.com

\begin{abstract}
The objective of this work was to improve the performances of manure spreaders, the rate flow been one of the factors, which influences the quality of the fertilizing activity. This paper presents the structural analysis that involves examination of the different components or elements that make up the conveyor acting system to discover their interrelationships and relative importance in the realization of the manure transport operation. Also, the article presents kinematic analysis (positions, velocities, accelerations) of a ratchet mechanism aiming to choose the optimal variant to provide the organic fertilizers ratio according to the agrotechnical requirements of the species that are cultivated in different orchards. The purpose of the structural analysis is to ensure the adequacy of the design from the point of view of safety and serviceability of the structure, to improve and validate the performance and reduce the need for costly prototypes or design changes later on. Kinetostatic analysis examines the behaviour of the ratchet mechanism under the action of the applied static forces and the inertial forces produced by the movement of the conveyor. Hence, the kinetostatic analysis determines the forces acting on the elements during the transport operation.
\end{abstract}

Keywords: structural analysis, kinematic analysis, loosening mechanism, manure spreaders.

\section{Introduction}

Fertilization is one of the major works within agricultural activities, either regarding large culture or horticulture or viticulture, therefore providing the necessary fertilizers in accordance with the agrotechnical requirements is an ongoing concern of researchers in the field.

More researches are known that have had aimed to improve the performance of organic manure spreaders, each work being directed on optimizing the constructive parameters of the spreading machine that influence the quality indices of the fertilization activity [1].

Organic fertilizing in orchards is an important work that requires different quantities of manure according to the fruit tree species, soil, climate changes etc. thus, implicitly, involving variation of the speed conveyor. In order to modify the quantity of manure that is transported by the chain conveyor and spread by the spreading device a ratchet mechanism was designed that performed several ratios of transmission. Researches were conducted to achieve several constructive types of chemical or organic fertilizer spreading machines [2-6] intended for use in large culture or in orchards, or vineyards. The research was directed towards achieving superior performance indicators of the fertilization work and reduced energy parameters. One of the work quality indicators is the distributed fertilizer rate per surface unit, which is influenced by the conveyor speed correlated with the aggregate movement speed.

There are several types of fertilizer conveyor drives depending on the power source of the aggregate: the hydrostatic drive or the mechanical drive (with ratchet mechanism or gear wheel and chain transmission). This paper refers to the analysis of the ratchet mechanism with the help of which driving of the conveyor of organic fertilizer spreader is performed, for proper sizing and positioning of the components.

In the structural and kinematic analysis of the ratchet mechanism that acts the chain conveyor of a manure spreader methods for solving mechanisms and also numerical methods have been used [7-17]. In order to write the equations necessary for mechanism analysis the independent contours method was used $[7 ; 10 ; 12-17]$.

To solve the systems of non-linear equations of the positions, the authors used Newton-Raphson and gradient methods, while to solve the systems of linear equations of velocities and accelerations the Gaussian elimination method was used $[8 ; 9 ; 11]$. 


\section{Materials and methods}

For the kinematic analysis of the mechanism calculation procedures drawn up by the authors were used. The systems of non-linear equations were obtained based on independent contours, and solving these systems of equations was made by the Newton-Raphson iterative method.

The kinematic scheme of the ratchet mechanism for driving the organic fertilizer conveyor of the manure spreader in orchards is presented in Fig. 1. To determine the kinematic parameters of the mechanism elements its structural analysis must been carried out first.

\section{Mechanism structural analysis}

As shown in the kinematic scheme of the mechanism (Fig. 1), the connection between elements 3 and 5 is made by means of a tension spring. The role of the spring is to keep the ratchet 5 and the gear wheel 4 in constant contact. The respective spring is equivalent to the hydraulic cylinder, as shown in Figure 2.

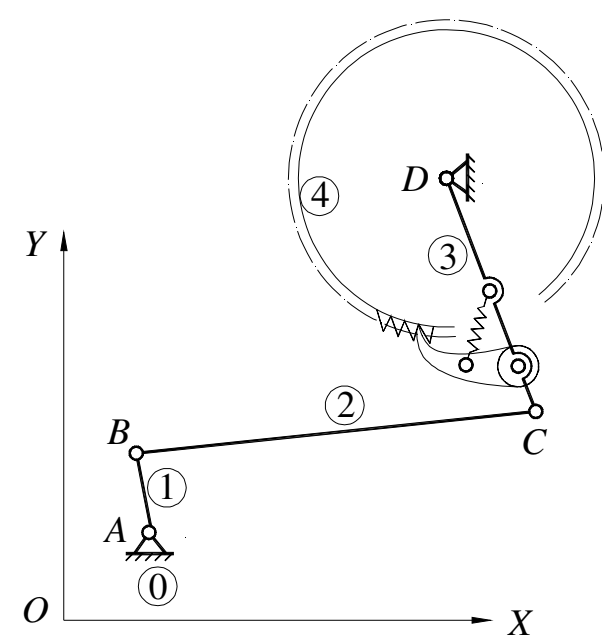

Fig. 1. Kinematic scheme of the mechanism

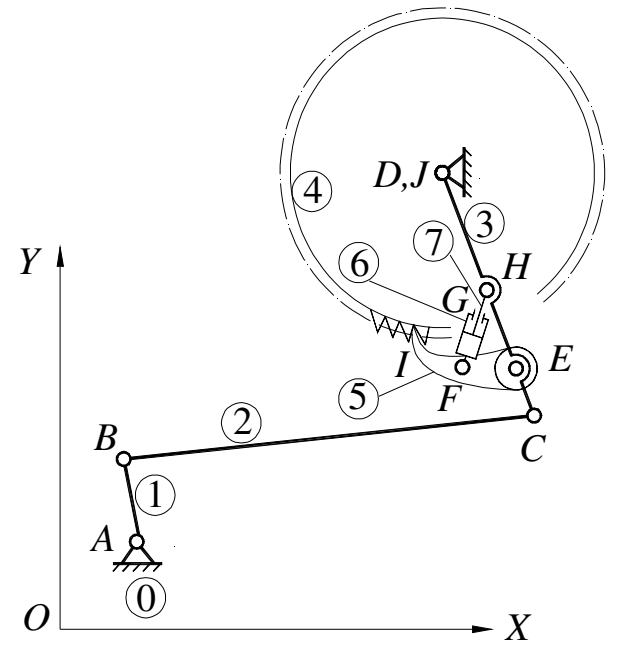

Fig. 2. Kinematic scheme of the mechanism

Taking into account the relative movements of the elements, it is noted that the mechanism has the following lower couplings: $A(0 R 1), B(1 R 2), C(2 R 3), D(3 R 0), E(3 R 5), F(5 R 6), G(6 R 7), H(3 R 7)$ and $J(4 R 0)$ [1-5]. Between the tooth of the gear wheel and the mechanism ratchet higher coupling I(4RT5) is formed.

The structural scheme of the mechanism is presented in Fig. 3.

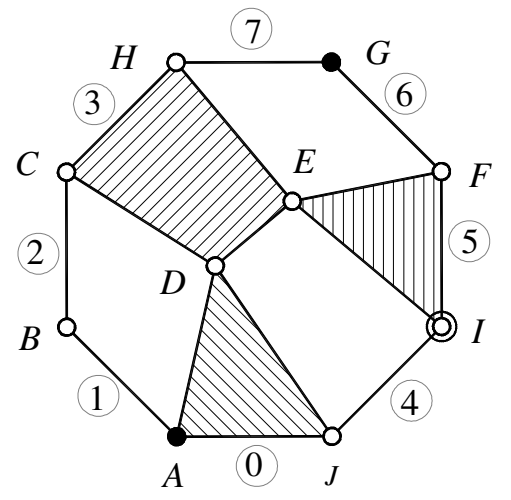

Fig. 3. Mechanism structural scheme

The mobile elements of the mechanism, according to the structural scheme in Fig. 3, are: 1(A,B), 2(B,C), 3(C,D,E,H), 4(J,I), 5(E,F,I), 6(F,G), 7(G,H).

Given the number of mobile elements and the number of kinematic couplings, results the mobility degree of the mechanism, namely: $M=2$, namely there must be two independent parameters. One of 
the independent parameters has the role to place the element 1 in relation to the positive direction of the $O X$ axis, while the second independent parameter is in the translational coupling $G$. The parameter in the translational coupling $G$ exists in the tensile strength of the spring itself, so it will not be studied.

In the present work the structural analysis has been made in order to determine the modular groups, which constitute the mechanism, so that in the main calculation program the corresponding procedures can be used.

In the mechanism construction the role of the spring is to keep the ratchet and the gear wheel in constant contact. This is achieved by the action of the spring elastic force. From here more mobility results. This mobility does not influence the kinematic parameters of elements 2 and 3, but it has the role to maintain the ratchet in contact with the gear wheel. In the mechanism theory, the ratchet is replaced by a hydraulic cylinder. This hydraulic cylinder has as independent parameter of the relative movement between the cylinder elements. As shown in the structural scheme (Fig. 3), the hydraulic cylinder together with element 5 form the so-called "driving dyad $R R \operatorname{TaR}(5,6,7)$ ", the independent parameter of which is the variable size $\mathrm{FH}$.

Fig. 4 shows a multipolar scheme, $a$ ) and the structural relation, $b$ ) in the structural and multipolar schemes it can be seen that the mechanism consists of base $Z(0)$, drive group $R(1)$, 1st aspect dyads, $R R R(2,3)$, drive dyads $R R T a R(5,6,7)$ and rodyad $\rho D(4)$.

a)

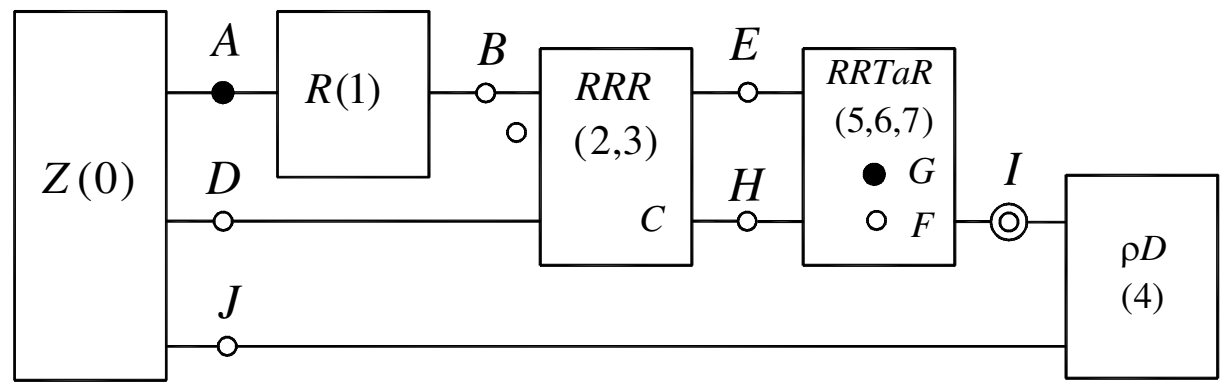

b)

$$
Z(0)+R(1)+R R R(2,3)+R R T a R(5,6,7)+\rho D(4)
$$

Fig. 4. a) Mechanism multipolar scheme; b) Structural relation

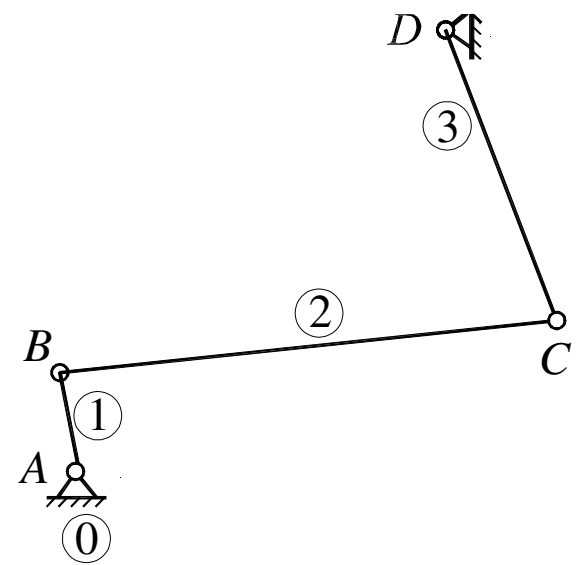

Fig. 5. Kinematic scheme of bar mechanism for which the kinematic analysis is made

\section{Mechanism kinematic analysis}

For the kinematic analysis of the mechanism there are several stages, namely:

1. drawing up the calculation program to determine the kinematic parameters of the mechanism elements, considering 36 equidistant positions of element $1\left(\Delta \varphi_{1}=0.1745329\right.$ radians);

2. tabular presentation of the values of angles formed by vectors $\overline{A B}, \overline{B C}$ and $\overline{D C}$, attached to the mechanism elements, with the positive direction of $O X$ axis; 
3. drawing the variation diagrams of mechanism element angles, velocities and angular accelerations, depending on the $\varphi_{1}$ angle;

4. drawing velocity and acceleration hodographs, corresponding to the points that mark the centre of $B$ and $C$ couplings.

Kinematic analysis of the ratchet mechanism consisted in determining the parameters of positions, velocities and accelerations, corresponding to all elements. For this, the initial position of the mechanism was defined (Fig. 6), DiadaRRR.m and GrupaMotR.m functions are applied, drawn up by the authors in the MATLAB syntax, to determine the kinematic parameters and the diagrams of the determined parameters are drawn.

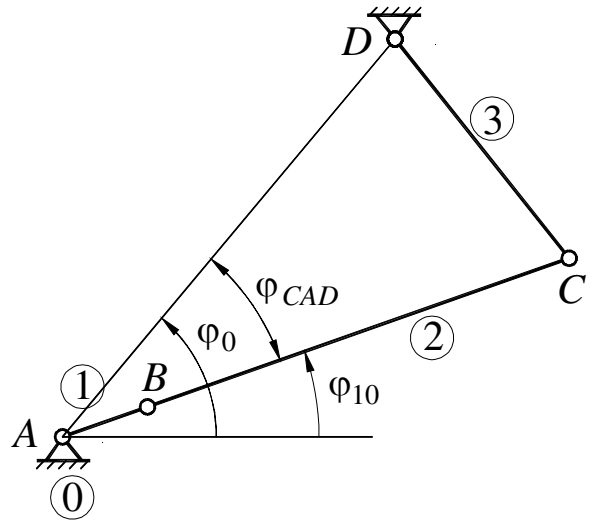

Fig. 6. Defining the initial position of the mechanism

Mechanism solving was made by several programming languages (Fortran, Turbo-Pascal, C++ etc.) or program packages (MATLAB, MathCAD). The results were the same. In the simulation of the mechanism functioning, the same independent parameters resulted.

\section{Results and discussion}

Using the methodology described above a concrete analysis of the mechanism that is part of the manure spreader, MGL-3, was made in order to optimize it.

In Fig. 7 the kinematic scheme of the entire mechanism is presented, highlighting the position parameters.

For the analysis of the mechanism the following are known:

1. kinematic scheme of the mechanism;

2. elements' dimension and positions of couplings adjacent to the base, as follows: $A B=0.060 \mathrm{~m}$, $B C=0.300 \mathrm{~m}, C D=0.182 \mathrm{~m}, X A=0.0 \mathrm{~m}, Y A=0.0 \mathrm{~m}, X D=0.170 \mathrm{~m}, Y D=0.260 \mathrm{~m}$.

3. mechanism initial position: $\varphi_{1}=\varphi_{10}=0.4616966 \mathrm{rad}$ (Fig. 6);

4. angular velocity of element $1: \omega_{1}=3.58979 \mathrm{~s}^{-1}$;

5. angular acceleration of element $1: \varepsilon_{1}=0.0 \mathrm{~s}^{-2}$.

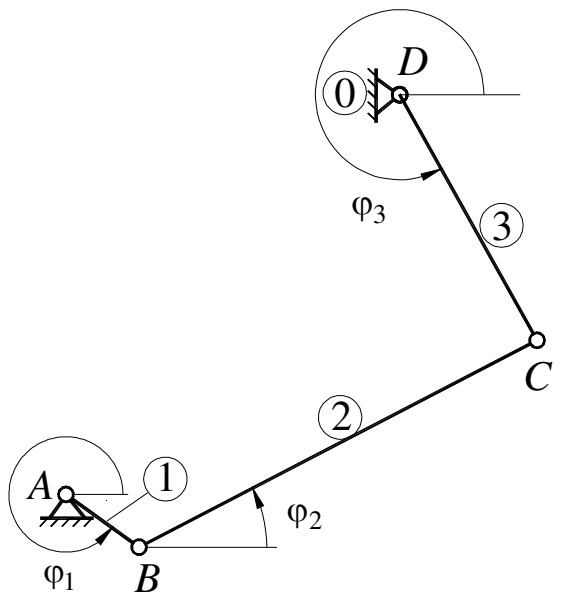

Fig. 7. Defining position kinematic parameters of the mechanism 
The calculations were made for 36 equidistant positions of element 1 , starting from the initial position: $\varphi_{1}=\varphi_{10}=0.461696 \mathrm{rad}$.

In table 1 the angles $\varphi_{1}, \varphi_{2}$ and $\varphi_{3}$, formed by vectors $\overline{A B}, \overline{B C}$ and $\overline{D C}$ with the positive direction of $A X$ axis, as well as the velocities and angular accelerations of elements 2 and 3 are presented.

Table 1

Angles, velocities and angular accelerations

\begin{tabular}{|c|c|c|c|c|c|c|c|}
\hline Poz. & $\begin{array}{l}\varphi_{1}, \\
\text { rad }\end{array}$ & $\begin{array}{l}\varphi_{2}, \\
\text { rad }\end{array}$ & $\begin{array}{l}\varphi_{3}, \\
\text { rad }\end{array}$ & $\begin{array}{c}\omega_{2}, \\
\mathrm{rad} \cdot \mathrm{s}^{-1}\end{array}$ & $\begin{array}{c}\omega_{3}, \\
\mathrm{rad} \cdot \mathrm{s}^{-1}\end{array}$ & $\begin{array}{c}\varepsilon_{2}, \\
\mathrm{rad}^{-2} \mathrm{~s}^{-2}\end{array}$ & $\begin{array}{c}\varepsilon_{3}, \\
\operatorname{rad} \cdot \mathrm{s}^{-2}\end{array}$ \\
\hline 0. & 0.4617 & 0.4617 & -0.5793 & -0.7180 & 0.0000 & -1.8113 & -5.9080 \\
\hline 1. & 0.6362 & 0.4248 & -0.5864 & -0.7964 & -0.2931 & -1.3734 & -6.0811 \\
\hline 2. & 0.8108 & 0.3847 & -0.6078 & -0.8475 & -0.5841 & -0.6886 & -5.8109 \\
\hline 3. & 0.9853 & 0.3430 & -0.6428 & -0.8597 & -0.8503 & 0.2135 & -5.0628 \\
\hline 4. & 1.1598 & 0.3019 & -0.6897 & -0.8248 & -1.0698 & 1.2319 & -3.9113 \\
\hline 5. & 1.3344 & 0.2636 & -0.7458 & -0.7405 & -1.2268 & 2.2184 & -2.5274 \\
\hline 6. & 1.5089 & 0.2306 & -0.8079 & -0.6120 & -1.3152 & 3.0274 & -1.1193 \\
\hline 7. & 1.6834 & 0.2047 & -0.8726 & -0.4506 & -1.3381 & 3.5633 & 0.1400 \\
\hline 8. & 1.8580 & 0.1871 & -0.9371 & -0.2704 & -1.3056 & 3.7994 & 1.1534 \\
\hline 9. & 2.0325 & 0.1784 & -0.9989 & -0.0855 & -1.2303 & 3.7649 & 1.9010 \\
\hline 10. & 2.2070 & 0.1786 & -1.0562 & 0.0923 & -1.1246 & 3.5194 & 2.4147 \\
\hline 11. & 2.3816 & 0.1871 & -1.1079 & 0.2543 & -0.9984 & 3.1283 & 2.7496 \\
\hline 12. & 2.5561 & 0.2030 & -1.1531 & 0.3950 & -0.8592 & 2.6486 & 2.9626 \\
\hline 13. & 2.7306 & 0.2252 & -1.1913 & 0.5112 & -0.7115 & 2.1239 & 3.1013 \\
\hline 14. & 2.9052 & 0.2523 & -1.2222 & 0.6013 & -0.5582 & 1.5849 & 3.1997 \\
\hline 15. & 3.0797 & 0.2832 & -1.2455 & 0.6654 & -0.4007 & 1.0529 & 3.2777 \\
\hline 16. & 3.2542 & 0.3166 & -1.2611 & 0.7041 & -0.2397 & 0.5429 & 3.3428 \\
\hline 17. & 3.4288 & 0.3513 & -1.2688 & 0.7188 & -0.0759 & 0.0673 & 3.3919 \\
\hline 18. & 3.6033 & 0.3861 & -1.2684 & 0.7114 & 0.0896 & -0.3630 & 3.4134 \\
\hline 19. & 3.7778 & 0.4201 & -1.2601 & 0.6844 & 0.2553 & -0.7379 & 3.3907 \\
\hline 20. & 3.9524 & 0.4524 & -1.2437 & 0.6406 & 0.4183 & -1.0492 & 3.3060 \\
\hline 21. & 4.1269 & 0.4822 & -1.2195 & 0.5834 & 0.5755 & -1.2924 & 3.1445 \\
\hline 22. & 4.3014 & 0.5090 & -1.1879 & 0.5161 & 0.7227 & -1.4682 & 2.8982 \\
\hline 23. & 4.4760 & 0.5323 & -1.1494 & 0.4417 & 0.8559 & -1.5832 & 2.5666 \\
\hline 24. & 4.6505 & 0.5519 & -1.1049 & 0.3629 & 0.9710 & -1.6494 & 2.1567 \\
\hline 25. & 4.8250 & 0.5675 & -1.0553 & 0.2818 & 1.0645 & -1.6817 & 1.6790 \\
\hline 26. & 4.9996 & 0.5792 & -1.0018 & 0.1997 & 1.1334 & -1.6960 & 1.1444 \\
\hline 27. & 5.1741 & 0.5869 & -0.9456 & 0.1170 & 1.1750 & -1.7071 & 0.5614 \\
\hline 28. & 5.3486 & 0.5906 & -0.8880 & 0.0335 & 1.1873 & -1.7268 & -0.0662 \\
\hline 29. & 5.5232 & 0.5902 & -0.8306 & -0.0512 & 1.1679 & -1.7636 & -0.7383 \\
\hline 30. & 5.6977 & 0.5856 & -0.7750 & -0.1383 & 1.1147 & -1.8214 & -1.4576 \\
\hline 31. & 5.8722 & 0.5767 & -0.7228 & -0.2287 & 1.0254 & -1.8986 & -2.2252 \\
\hline 32. & 6.0467 & 0.5633 & -0.6759 & -0.3231 & 0.8976 & -1.9857 & -3.0358 \\
\hline 33. & 6.2213 & 0.5452 & -0.6362 & -0.4216 & 0.7298 & -2.0626 & -3.8696 \\
\hline 34. & 6.3958 & 0.5222 & -0.6056 & -0.5229 & 0.5217 & -2.0949 & -4.6829 \\
\hline 35. & 6.5703 & 0.4944 & -0.5861 & -0.6238 & 0.2760 & -2.0319 & -5.3991 \\
\hline 36. & 6.7449 & 0.4617 & -0.5793 & -0.7180 & 0.0000 & -1.8113 & -5.9080 \\
\hline
\end{tabular}

In Fig. 8, 9 and 10, the variation diagrams of the angles, velocities and angular accelerations of mechanism elements 2 and 3 are presented.

For different positions (given by the angle $\varphi_{1}$ ) of the driving element 1 , which has a rotational motion with constant angular velocity, it is observed that the driven elements, 2 and 3, rotate at variable angular velocities, implicit variable angular accelerations. 
This shows the necessity of the mechanism kinetostatic analysis in order to adequately dimension the elements as well as to find appropriate positions of the D-joint to reduce stress in bars.

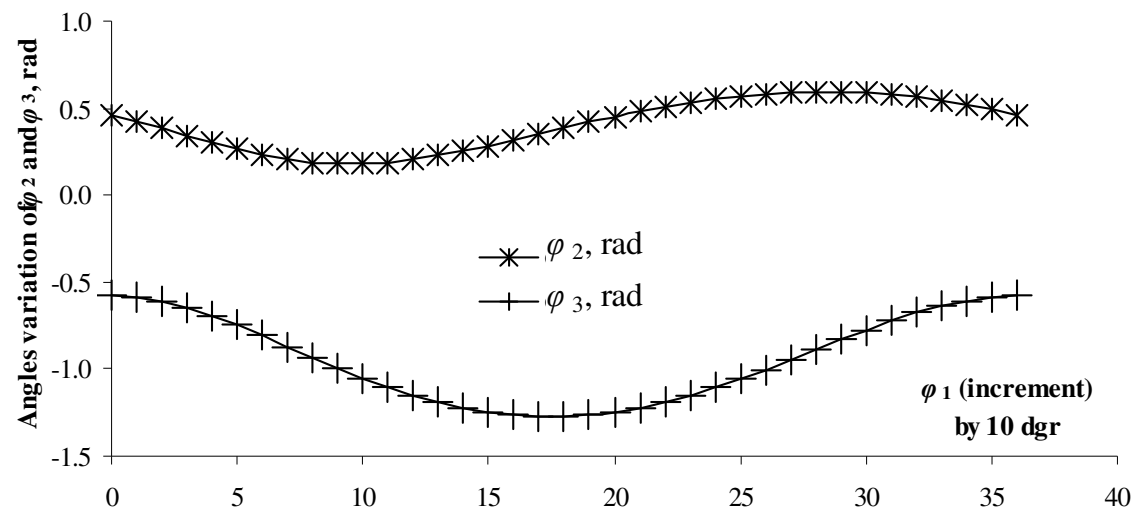

Fig. 8. Variation diagrams of angles $\varphi_{2}$ and $\varphi_{3}$

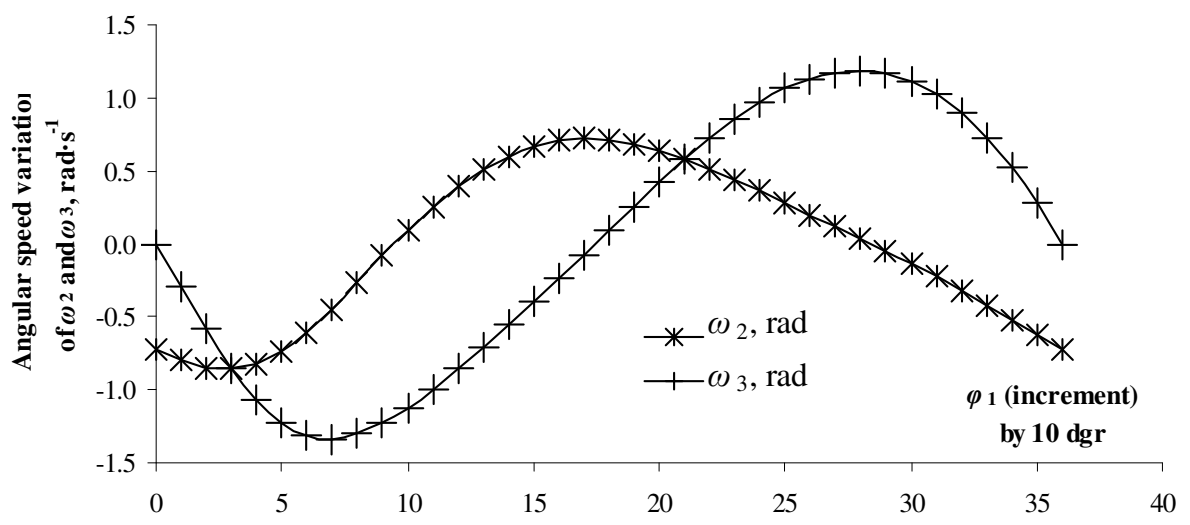

Fig. 9. Variation diagrams of angular accelerations $\omega_{2}$ and $\omega_{3}$

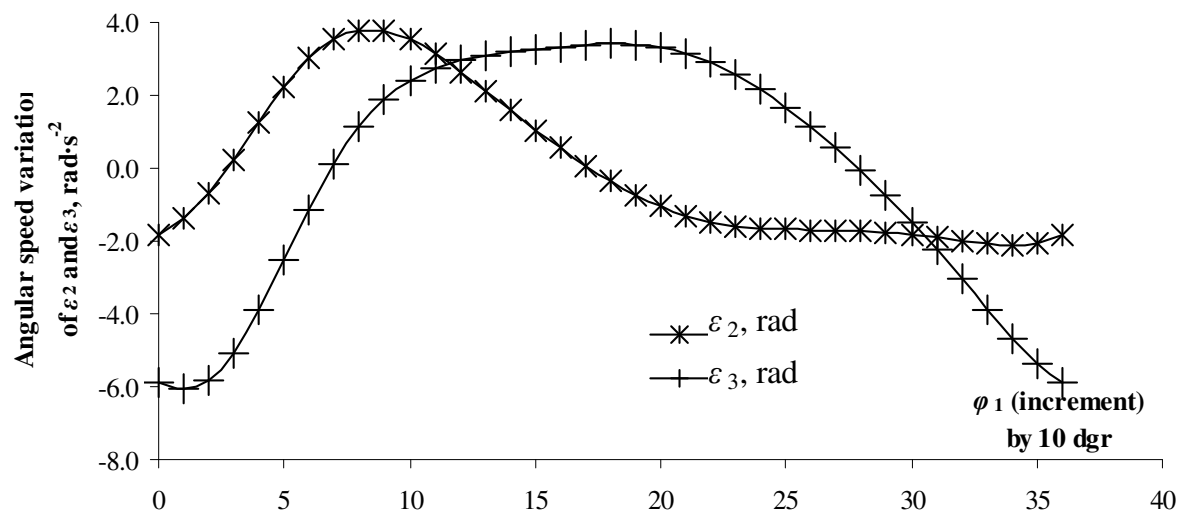

Fig. 10. Variation diagrams of angular accelerations $\varepsilon_{2}$ and $\varepsilon_{3}$

\section{Conclusions}

1. Kinematic parameter determination of the mechanism elements was done using calculation procedures already known [11-15].

2. Mechanism solving was made by several programming languages (Fortran, Turbo-Pascal, C++ etc.) or program packages (MATLAB, MathCAD). The results were the same. In the simulation of the mechanism functioning the same independent parameters resulted.

3. For the kinematic analysis of the mechanism calculation procedures drawn up by the authors were used. Calculation procedures for each modular group of the mechanism structure presented in this paper by the authors of the article were drawn using MATLAB syntax. 
4. The calculus results were presented both in tabular form and as diagrams. The results show variation of the angular speed and angular acceleration of the driven elements 2 and 3, depending on the position of the driving element 1.

5. Kinematic analysis of the mechanism precedes its kinetostatic analysis.

- kinematics analysis will be the basis of the mechanism kinetostatic analysis (determining the reactions in the mechanism kinematic couplings as well as its driving moment);

- based on the results of the kinematic analysis, optimization of the mechanism will be made so that it operates at optimum pressure angles, the elements of the mechanism have optimal dimensions, the energy consumed for starting the mechanism be minimum etc;

6. The forces and torques acting on the mechanism elements and also the acting torque in the driving couple $A$ will be determined in kinetostatic analysis that will be performed in the next study.

\section{References}

1. Miclet D., Piron E, Venel S. etc. Mass flow control for the manure spreader. Proceedings of "International Conference on Agricultural Engineering-AgEng 2010: towards environmental technologies", Sept 6-8, 2010, Clermont-Ferrand, France, p.10.

2. Popa L., Pirna I., Nedelcu A. etc. Manure spreading machine of 5 tons capacity, MG-5. Research Journal of Agricultural Science. vol. 41(2), 2009, pp. $489 \ldots 493$.

3. Popa L., Ştefan V., Andrei L.V. etc. Researches regarding the manufacturing of a machine for chemical fertilizers and amendments spreading, MA-3.6, INMATEH-Agricultural Engineering Journal, vol. 27, no.1, 2009, pp. 54...59.

4. Ştefan V., Popa L., Ciuperca R. etc. Manure fertilizers-Agrotechnical recommendations. Proceedings of International Symposium ISB-INMA'THE "Agricultural and mechanical engineering", Oct. 30-31, 2014, Bucharest, Romania, pp. 387-392.

5. Ştefan (Popa) V., Ciupercă R., Popa L. etc. The influence of physical characteristics of solid organic fertilizers on quality of land spreading, INMATEH-Agricultural Engineering Journal, vol. 46, no.2, 2015, pp. 77-84.

6. Ştefan V., Popa L., David L. etc. Considerations on physical and mechanical properties of solid organic fertilizers. Proceedings of " 4 th International Conference on Thermal Equipment, Renewable Energy and Rural Development" TE-RE-RD 2015, June 4-6, 2015, Posada, Romania, pp. 369-374.

7. Artobolevski I.I. Théorie des Mécanismes et des Machines (Theory of Mechanisms and Machines). Moscow: Ed. Mir, 1977. 453 p. (In French).

8. Demidovich B., Maron A.I. Éléments de calcul numérique. $2^{\text {nd }}$ edition. Moscow: Ed. Mir, 1987. 717 p. (In French).

9. Dorn W.S., Mc Cracken D.D. Metode numerice cu programe în FORTRAN IV. Bucureşti: Editura Tehnică, 1976. 468 p. (In Romanian).

10. Duca C., Buium Fl., ş.a. Mecanisme. Iaşi: Editura Gh. Asachi, 2003. 481 p. (In Romanian).

11. Moise V., Maican E., Moise Şt. I. Metode numerice în inginerie. Bucureşti: Ed. Bren, 2003. 305 p. (In Romanian).

12. Moise V., Simionescu I., Ene M. etc. Analiza mecanismelor aplicate. Bucureşti: Editura Printech, 2008. 282 p. (In Romanian).

13. Pelecudi Chr. Precizia mecanismelor. Bucureşti: Editura Academiei Republicii Socialiste Romania, 1975. 398 p. (In Romanian).

14. Popescu I. Proiectarea mecanismelor plane. Institutul Politehnic București, 1977, 577 p, (In Romanian).

15. Pelecudi Chr., Maroş D., Merticaru V. etc. Mecanisme, Bucureşti: Editura Didactică şi Pedagogică, 1985. 394 p. (In Romanian).

16. Simionescu I., Moise V. Mecanisme. București: Editura Tehnică. 1999, 238 p. (In Romanian).

17. Uicker J.J., Pennock G.R., Shigley J. E. Theory of Machines and Mechanisms. 4th Edition. New York: Oxford University Press, 2011. 928 p. 